University of Nebraska - Lincoln

DigitalCommons@University of Nebraska - Lincoln

Faculty Publications: Department of Entomology

December 1984

\title{
Temperature-dependent Model for Development of Nondiapausing Sorghum Midges (Diptera: Cecidomyiidae)
}

Frederick P. Baxendale

University of Nebraska-Lincoln, fbaxendale1@unl.edu

G. L. Teetes

Texas A \& M University

P. J. H. Sharpe

Texas A \& M University

H. Wu

Texas A \& M University

Follow this and additional works at: https://digitalcommons.unl.edu/entomologyfacpub

Part of the Entomology Commons

Baxendale, Frederick P.; Teetes, G. L.; Sharpe, P. J. H.; and Wu, H., "Temperature-dependent Model for Development of Nondiapausing Sorghum Midges (Diptera: Cecidomyiidae)" (1984). Faculty Publications: Department of Entomology. 145.

https://digitalcommons.unl.edu/entomologyfacpub/145

This Article is brought to you for free and open access by the Entomology, Department of at DigitalCommons@University of Nebraska - Lincoln. It has been accepted for inclusion in Faculty Publications: Department of Entomology by an authorized administrator of DigitalCommons@University of Nebraska - Lincoln. 


\title{
Temperature-dependent Model for Development of Nondiapausing Sorghum Midges (Diptera: Cecidomyiidae)
}

\author{
F. P. BAXENDALE, ${ }^{1}$ G. L. TEETES, ${ }^{2}$ P. J. H. SHARPE, ${ }^{3}$ AND H. WU ${ }^{3}$ \\ Department of Entomology, Texas A\&M University, \\ College Station, Texas 77843
}

\begin{abstract}
Environ. Entomol. 13: 1572-1576 (1984)
ABSTRACT Constant-temperature development data were used to construct a temperature-dependent, two-component model for the development of nondiapausing sorghum midges, Contarinia sorghicola (Coquillett), from egg to adult emergence. When constant temperatures were between 20 and $36^{\circ} \mathrm{C}$, nondiapausing midges completed development and emerged as adults. Development times decreased as temperature increased. Above $34^{\circ} \mathrm{C}$ however, development times increased and numbers of emerged adults declined. A coupled poikilotherm rate equation and cumulative Weibull distribution provided accurate descriptions of the developmental data. Model simulations compared favorably with observed emergence of adult midges from johnsongrass and sorghum in the field throughout the season.
\end{abstract}

FUNDAMENTAL TO THE development of a comprehensive pest management system for the sorghum midge, Contarinia sorghicola (Coquillett), is the construction of a seasonal-dynamics model around which grower-oriented management strategies can be designed. Sorghum midges overwinter underground as diapausing larvae within spikelets of grasses in the genus Sorghum (Young and Teetes 1977). In the spring, adults emerge from the soil and oviposit the season's first generation in nearby flowering johnsongrass, Sorghum halepense (L.) Pers. This wild host maintains the first one to three spring generations until flowering sorghum, Sorghum bicolor (L.) Moench, becomes available (Dean 1911, Thomas and Cate 1971, Roth and Pitre 1975, Baxendale 1980). Once early-planted sorghum begins to flower, most midges disperse to sorghum where economic densities can be reached in a single additional generation (Baxendale 1980). A diagrammatic representation of the seasonal dynamics of the sorghum midge in central Texas is presented in Fig. 1.

Baxendale et al. (1984) used the modeling approaches of Sharpe and DeMichele (1977) and Wagner et al. (1984a,b) to construct a temperature-dependent model for the spring emergence of overwintered sorghum midges. In this study, constant-temperature development data were used to construct a two-component model of sorghum midge development from egg to adult emergence of nondiapausing generations in the field. The model was validated using observed midge emergence from wild johnsongrass and sorghum and is

\footnotetext{
${ }^{1}$ Present address: Dept. of Entomology, Univ. of Nebraska, Lincoln, NE 68583-0816.

2 Dept. of Entomology, Texas A\&M Univ., College Station, TX 77843.

${ }^{3}$ Biosystems Res. Group, Dept. of Industrial Engineering, Texas A \&M Univ., College Station, TX 77843.
}

suitable for incorporation, along with the spring emergence model of Baxendale et al. (1984), into a larger seasonal-dynamics model for the midge.

\section{Materials and Methods}

Constant-temperature Studies. Midge-susceptible sorghum plants (ATx3042 $\times$ RTx2737) were grown in pots in the field at the Texas A\&M University Plantation near College Station. When plants reached the boot stage of development (Vanderlip 1972), fine-mesh saran cages, sealed at the base with Velcro strips, were placed over plant boots to prevent oviposition by naturally occurring midges as panicles emerged and began to flower. When panicles were at $50 \%$ anthesis, rachis branches were excised leaving only 500 to 600 spikelets with yellow anthers exposed (susceptible stage) available for midge oviposition. Ten sorghum midge females, aspirated from nearby panicles, were introduced into each cage. This procedure was carried out between 0800 and 0900 hours when newly emerged females had mated and were just beginning to oviposit (Fisher et al. 1982). Plants and midges were taken to the laboratory where they were placed in environmental chambers maintained at selected constant temperatures. Four plants (replicates) were placed at each of 11 selected temperatures $(20,22,24,26,28,30$, $32,34,35,36$, and $38^{\circ} \mathrm{C}$ ) with L:D 14:10 photoperiod and ca. $65 \%$ RH. Emerged adults were removed from cages and counted daily throughout the emergence period.

Emergence Studies in the Field. Emergence of nondiapausing sorghum midges in the field was monitored in johnsongrass and sorghum (ATx3042 $\times$ RTx2737) at the Texas A\&M University Plantation near College Station, during the spring and summer of 1980 . Between 0800 and 1000 hours, one female sorghum midge was aspi- 


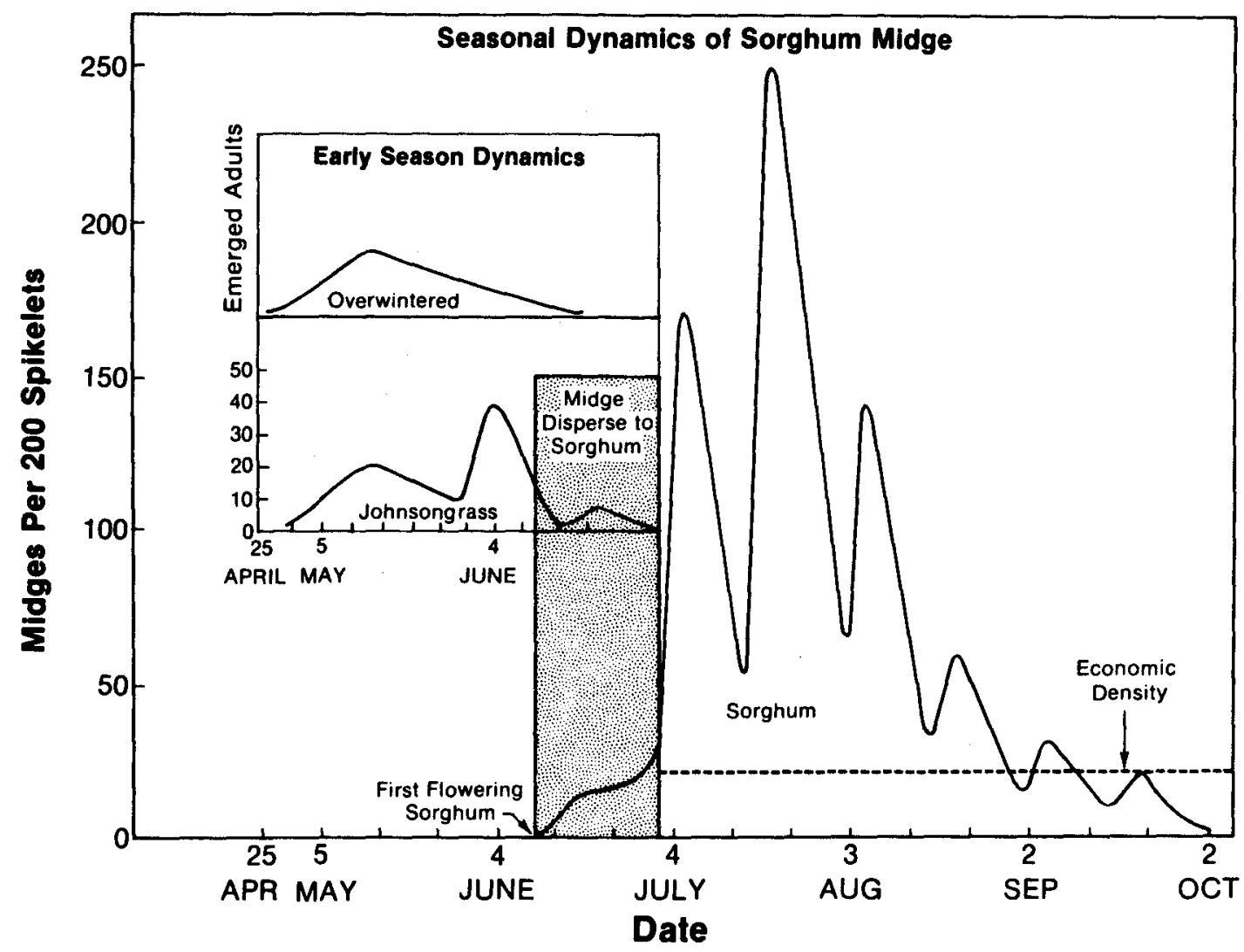

Fig. 1. Seasonal dynamics of the sorghum midge in central Texas (based on data from Baxendale [1980]).

rated from a nearby panicle and was introduced into each of 15 saran cages covering johnsongrass or sorghum panicles in $50 \%$ anthesis. This procedure was carried out on two separate occasions in johnsongrass (25 May and 31 May), and four times in sorghum (23 June, $10 \mathrm{July}, 18 \mathrm{July}$, and $24 \mathrm{July}$ ). In all cases, panicles had been protected from natural midge oviposition before the introduction of female midges. Adult progeny were removed from cages and counted daily throughout the emergence period. Ambient temperatures were recorded continuously by thermographs maintained at the field site.

Analytical Procedures. Analytical procedures were similar to those described by Baxendale et al. (1984). Constant-temperature data were used to construct a temperature-dependent, two-component model for the development from egg to adult emergence of nondiapausing sorghum midges. The poikilotherm rate equation of Sharpe and DeMichele (1977), as modified by Schoolfield et al. (1981), was fitted to median emergence rates (Wagner et al. 1984a); and a cumulative Weibull function was fitted to the standard normalized distribution of emergence times (Wagner et al. 1984b). Parameter estimates for both the rate and distribution functions were obtained from the computer programs of Wagner et al. (1984a,b). The two model components were coupled and used to simulate field emergence.

Temperature inputs to the simulation model consisted of 8 daily temperatures spaced at 3-h intervals. Input temperatures were generated by fitting a sinusoidal function to daily maximum and minimum temperatures (Baxendale 1983).

Table 1. Summary statistics for development from egg to adult emergence of nondiapausing sorghum midges maintained at selected constant temperatures

\begin{tabular}{cccc}
\hline & Temp & $\begin{array}{c}\text { Total no. of } \\
\text { emerged } \\
\text { ( } \mathrm{C} \text { C) }\end{array}$ & $\begin{array}{c}\text { Development from egg } \\
\text { to adult emergence }\end{array}$ \\
\cline { 3 - 4 } & & $\begin{array}{c}\text { Median } \\
\text { (days) }\end{array}$ & $\begin{array}{c}\text { Mean (days) } \\
\pm \text { SEM }\end{array}$ \\
\hline 20 & 577 & 27.9 & $28.5 \pm 0.14$ \\
22 & 1,419 & 22.5 & $23.0 \pm 0.07$ \\
24 & 807 & 20.2 & $20.5 \pm 0.09$ \\
26 & 803 & 17.6 & $18.1 \pm 0.09$ \\
28 & 796 & 15.7 & $16.0 \pm 0.08$ \\
30 & 366 & 14.2 & $14.6 \pm 0.10$ \\
32 & 133 & 12.9 & $13.3 \pm 0.15$ \\
34 & 158 & 11.4 & $11.8 \pm 0.16$ \\
35 & 12 & 11.7 & $12.4 \pm 0.66$ \\
36 & 3 & 11.8 & $11.9 \pm 0.33$ \\
38 & 0 & - & - \\
\hline
\end{tabular}




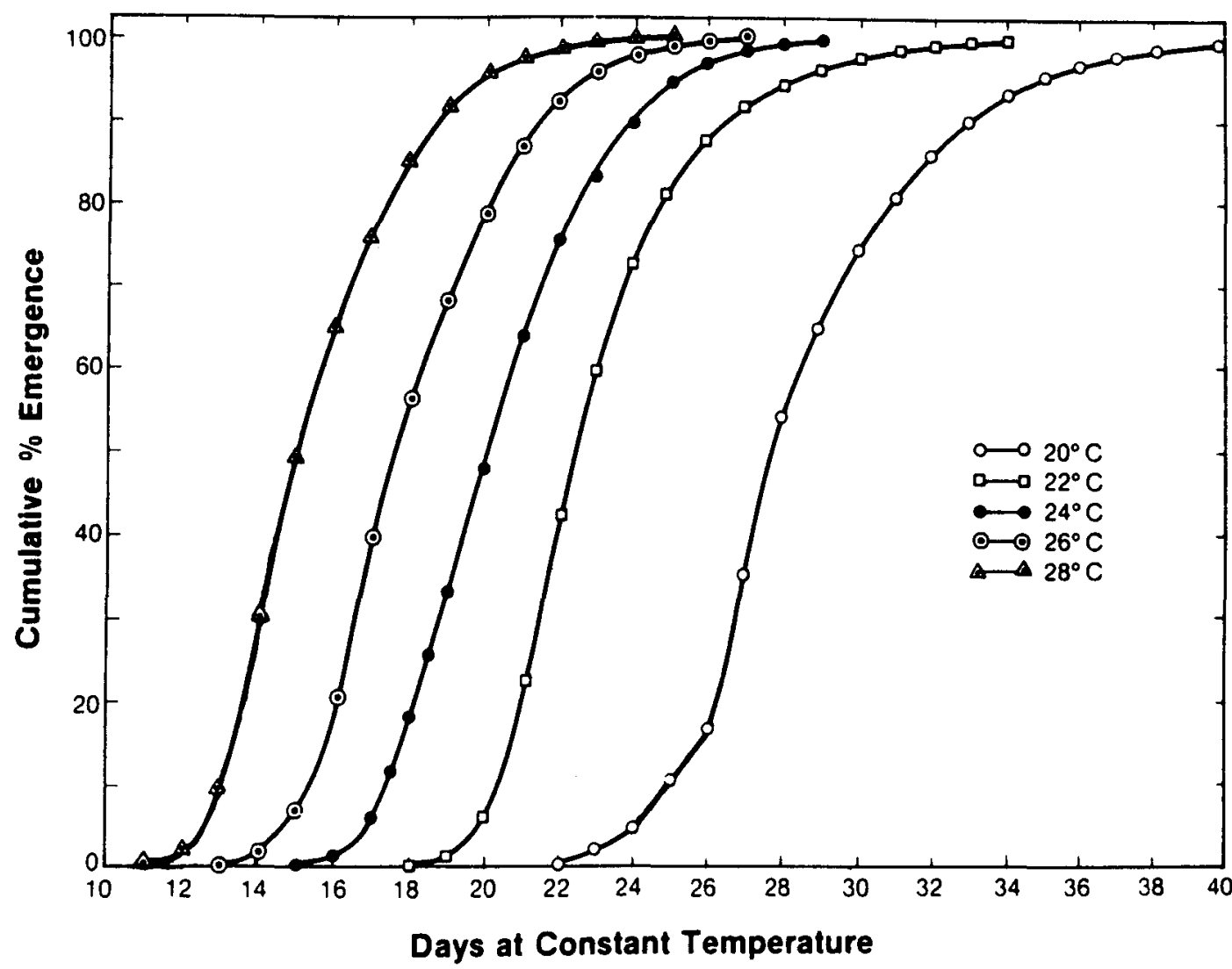

Fig. 2. Representative distributions of development from egg to adult emergence for nondiapausing sorghur midges at constant temperatures.

Model validation involved comparisons of simulated and observed emergence in the field. Mean absolute differences between predicted and observed cumulative percentages of emergence served as measures of model performance.

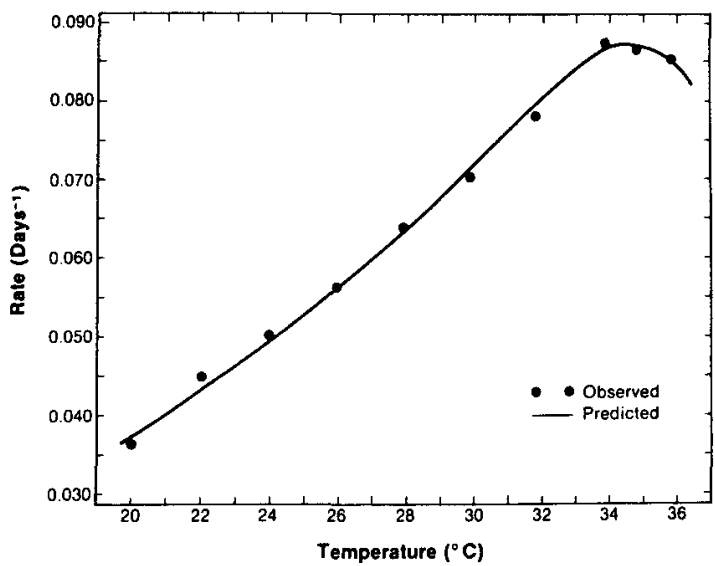

Fig. 3. Poikilotherm rate model (solid lines) fitted to median emergence rates (dots) for nondiapausing sorghum midges at constant temperatures.

\section{Results and Discussion}

Constant-temperature Studies. Nondiapausing sorghum midges completed development and emerged as adults when temperatures were between 20 and $36^{\circ} \mathrm{C}$ (Table 1). Median emergence times ranged from 27.9 days at $20^{\circ} \mathrm{C}$ to 11.4 days at $34^{\circ} \mathrm{C}$. When temperatures exceeded $34^{\circ} \mathrm{C}$, how ever, times until adults emerged increased and numbers of emerged adults declined sharply.

Table 2. Parameter estimates and asymptotic 95\% confidence intervals of the four-parameter poikilotherm model fitted to median development rates (1/median times, for egg to adult emergence of nondiapausing sorghur midges

\begin{tabular}{lrrrrc}
\hline & RHO25 & \multicolumn{1}{c}{ HA } & \multicolumn{1}{c}{ TH } & \multicolumn{1}{c}{ HH } & $R^{2}$ \\
\hline Parameter & & & & & \\
estimate & 0.0523 & $10,662.78$ & 311.82 & $111,731.5$ & 0.994 \\
$95 \%$ CI & 0.0017 & $1,827.41$ & 2.43 & $121,289.9$ & - \\
\hline
\end{tabular}

${ }^{a}$ RHO25, development rate at $25^{\circ} \mathrm{C}$ assuming no enzyme in activation (time $\left.e^{-1}\right) ; H A$, enthalpy of activation of the reactior that is catalyzed by a rate-controlling enzyme (cal/mol); $T H$ Kelvin temperature at which the rate-controlling enzyme is $1 /$ active and $1 / 2$ high-temperature inactive; $H H$, change in enthalpy associated high-temperature inactivation of the enzyme (cal $/ \mathrm{mol})$ 
Table 3. Parameter estimates and asymptotic $95 \%$ confidence intervals of a cumulative Weibull distribution fitted to the standard normalized distribution for egg to adult emergence of nondiapausing sorghum midges

\begin{tabular}{lcccc}
\hline & Gamma $^{a}$ & Beta & Eta & $R^{2}$ \\
\hline Parameter estimate & 0.8085 & 1.7269 & 0.2391 & 0.999 \\
95\% CI & 0.0103 & 0.1018 & 0.0111 & - \\
\hline
\end{tabular}

a Gamma, beta, and eta are parameters estimated by the nonlinear regression procedure.

The effects of temperature on developmental rates resulted in adult emergence distributions at different temperatures being displaced through time. This displacement was apparent in the cumulative emergence distributions (Fig. 2).

Temperature-dependent Model for Nondiapausing Sorghum Midges. When the poikilotherm model was fitted to median emergence rates, it accurately described $\left(R^{2}=0.994\right)$ the relationship between temperature and rate of development for nondiapausing sorghum midges (Fig. 3). Inspection of the curve of rate versus temperature and Arrhenius plot (not shown) indicated that the computer had correctly selected a four-parameter form of the model (with high temperature inhibition) to describe the data. Parameter estimates and their asymptotic $95 \%$ confidence intervals are given in Table 2.

The cumulative Weibull distribution was fitted to the standard normalized distribution of emergence times with similarly good results $\left(R^{2}=0.999\right)$. Parameter estimates and their asymptotic 95\% confidence intervals are presented in Table 3.

Emergence in the Field and Model Validation. The first critical test of the model involved its ability to predict adult emergence from johnsongrass. Since midges spend the first two or three generations in johnsongrass (Baxendale 1980), it was essential that midge emergence be accurately predicted from this wild host for the model to be useful as a component of a seasonal-dynamics model. On both test occasions the model provided accurate predictions of adult emergence from johnsongrass (Fig. 4). Mean absolute differences between predicted and observed adult emergence in the field were small, with only 2.55 and $4.04 \%$ differences for eggs deposited on 25 May (Fig. 4A) and 31 May (Fig. 4B), respectively.

The model also accurately predicted adult emergence from sorghum. On all four occasions, model simulations compared well with observed adult emergence (Fig. 5): Mean absolute differences between simulated and observed cumulative percentages of adult midge emergence were as low as $1.95 \%$ for eggs deposited on 23 June (Fig. 5A) to $5.61 \%$ for eggs deposited on 18 July (Fig. 5C). The only major inconsistency between observed and predicted emergence data resulted from the tendency of the model to predict emergence
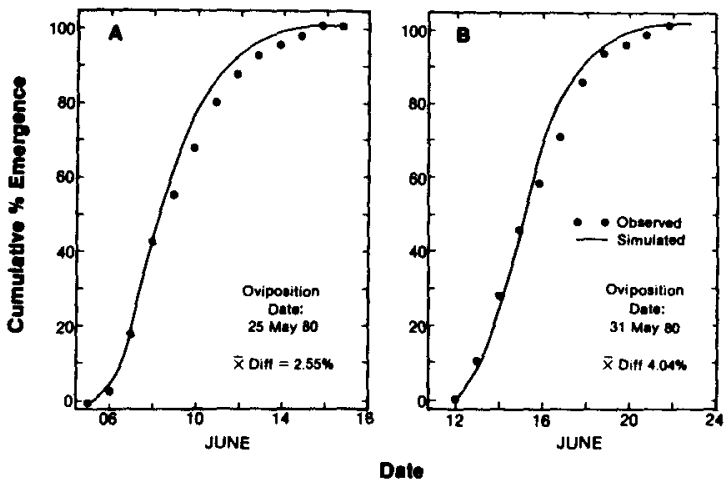

Fig. 4. Field emergence of nondiapausing sorghum midges from johnsongrass (dots) on two occasions, compared with model predictions (solid lines).

slightly early during the latter portions of some emergence periods.

The model should provide accurate predictions of adult emergence in johnsongrass and sorghum throughout the season. It may be necessary, however, to incorporate an adjustment factor correcting for delays in emergence due to rainfall (see Baxendale et al. 1984). Since no rain fell during any of the emergence periods, it was not possible to establish a precipitation threshold for emerging adults in this study.

Construction of a seasonal-dynamics model for
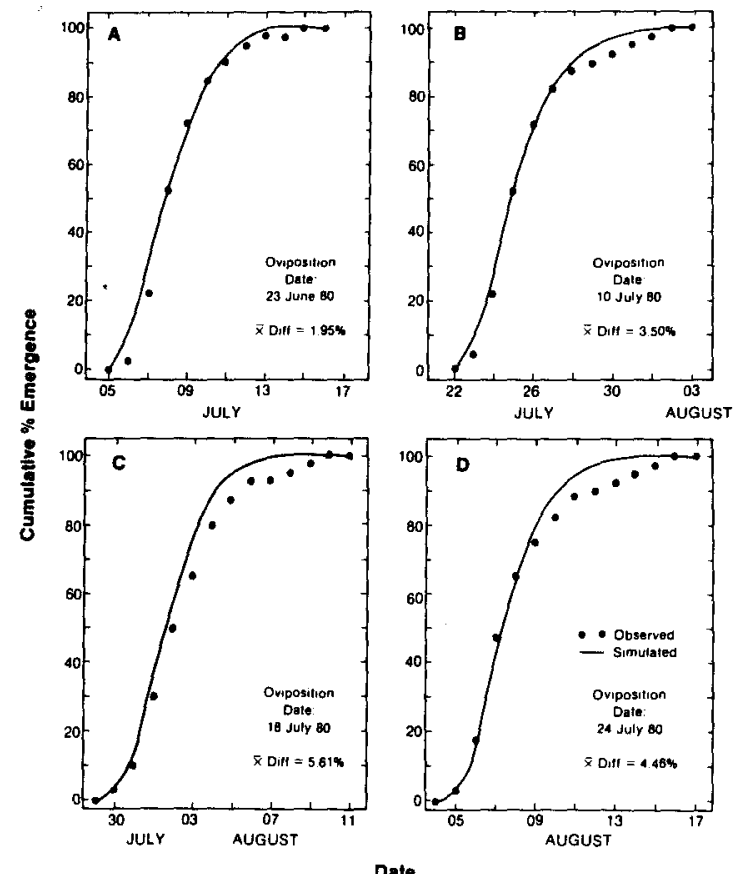

Fig. 5. Field emergence of nondiapausing sorghum midges from sorghum (dots) on four occasions, compared with model predictions (solid lines). 
the sorghum midge will involve coupling the spring emergence model of Baxendale et al. (1984) with the nondiapause generation model developed in this study, with the addition of fecundity and mortality data for prediction of changes in population density. The model should provide reliable forecasts of economic sorghum midge densities throughout the temperate range of the pest.

\section{Acknowledgment}

Approved as TA19568 by the director of the Texas Agric. Exp. Stn. This research was supported in part by grant AID/DSAN/XII/G-0149 from the Agency for International Development, Washington, D.C. Project H6216.

\section{References Cited}

Baxendale, F. P. 1980. Diapause termination, overwintering emergence and the seasonal abundance of the sorghum midge, Contarinia sorghicola (Coquillett) and its parasites. M.S. thesis, Texas A\&M University, College Station.

1983. Modeling seasonal development of the sorghum midge, Contarinia sorghicola (Coquillett). Ph.D. dissertation, Texas A\&M University, College Station.

Baxendale, F. P., G. L. Teetes, and P. J. H. Sharpe. 1984. Temperature-dependent model for sorghum midge (Diptera: Cecidomyiidae) spring emergence. Environ. Entomol. 13: 1566-1571.

Dean, W. H. 1911. The sorghum midge. U.S. Dep. Agric. Entomol. Bull. 85: 39-58.
Fisher, R. W., G. L. Teetes, and F. P. Baxendale. 1982. Effects of time of day and temperature on sorghum midge emergence and oviposition. Tex. Agric. Exp. Stn. Prog. Rep. 4029.

Roth, J. P., and H. N. Pitre. 1975. Seasonal incidence and host plant relationships of the sorghum midge in Mississippi. Ann. Entomol. Soc. Am. 68: 654-658.

Schoolfield, R. M., P. J. H. Sharpe, and C. E. Magnuson. 1981. Nonlinear regression of biological temperature-dependent rate models based on absolute reaction-rate theory. J. Theor. Biol. 88: 719-731.

Sharpe, P. J. H., and D. W. DeMichele. 1977. Reaction kinetics of poikilotherm development. Ibid. 64: 649-670.

Thomas, J. G., and J. R. Cate, Jr. 1971. The sorghum midge and its control. Tex. Agric. Exp. Stn. Prog. Rep. 2863.

Vanderlip, R. L. 1972. How a sorghum plant develops. Kans. Agric. Exp. Stn. Dep. Agron. Contrib. 1203.

Wagner, T. L., H. Wu, P. J. H. Sharpe, R. M. Schoolfield, and R. N. Coulson. 1984a. Modeling insect development rates: a literature review and application of biophysical model. Ann. Entomol. Soc. Am. 77: 208-225.

Wagner, T. L., H. Wu, P. J. H. Sharpe, and R. N. Coulson. 1984b. Modeling distributions of insect development time: a literature review and application of the Weibull function. Ibid. 77: 475-487.

Young, W. R., and G. L. Teetes. 1977. Sorghum entomology. Annu. Rev. Entomol. 22: 193-218.

Received for publication 30 April 1984; accepted 6 August 1984. 